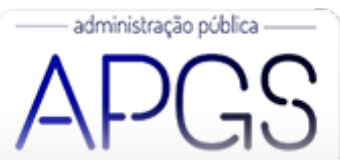

Administração Pública e Gestão Social ISSN: 2175-5787

apgs@ufv.br

Universidade Federal de Viçosa

Brasil

\title{
Organizing e Gestão Ordinária na Economia Criativa Local
}

da Silva, Ítalo; Karolina Dias, Pâmela; Cavalcante dos Santos, Elisabeth

Organizing e Gestão Ordinária na Economia Criativa Local

Administração Pública e Gestão Social, vol. 13, núm. 3, 2021

Universidade Federal de Viçosa, Brasil

Disponible en: https://www.redalyc.org/articulo.oa?id=351566982003 
Casos de Ensino

\section{Organizing e Gestão Ordinária na Economia Criativa Local}

Organizing and Ordinary Management in the Local Creative Economy

Organización y Gestión ordinaria en la economía creativa local

Ítalo da Silva

Programa de Pós-Graduação em Gestão Inovação e

Consumo (PPGIC). Universidade Federal de Pernambuco

(UFPE), Brasil

italohenriquedefreitas@gmail.com

Pâmela Karolina Dias

Programa de Pós-Graduação em Gestão Inovação e

Consumo (PPGIC). Universidade Federal de Pernambuco

(UFPE), Brasil

pamela_dias2009@hotmail.com

Elisabeth Cavalcante dos Santos

Programa de Pós-Graduação em Gestão Inovação e

Consumo (PPGIC). Universidade Federal de Pernambuco

(UFPE), Brasil

elisabethcsantos@gmail.com
Redalyc: https://www.redalyc.org/articulo.oa? $\mathrm{id}=351566982003$

Recepción: 27 Abril 2020

Aprobación: 24 Noviembre 2020

Publicación: 01 Julio 2021

\section{Resumo:}

Contexto do caso: Este caso utiliza o contexto da economia criativa local e apresenta os modos de gestão inerentes de duas organizações atuantes no segmento de cultura e de tecnologias de comunicação e informação, ambas demandando resoluções de problemas organizacionais pertinentes ao seu contexto de trabalho.

Dilema do caso: Aciona-se os conceitos de organizing da teoria das organizações e gestão ordinária, propondo que os estudantes pensem em soluçôes para os problemas e especificidades enfrentados pelas organizações no dia a dia. As soluções para esses problemas cotidianos podem estar relacionadas às limitações de recursos físicos, financeiros, operacionais e técnicos que permitam a manutenção e a sobrevivência das organizações atinentes às suas demandas gerenciais.

Fechamento do caso: A narrativa do caso para ensino foi construída a partir da realização de entrevistas semiestruturadas, observação participante e utilização de dados públicos da secretaria municipal da cidade de Caruaru (PE), portanto, a ideia central deste caso para ensino é propor uma discussão sobre a gestão feita a partir do cotidiano de duas organizações com atuações em segmentos diferentes, mas que estão presentes no mesmo contexto da economia criativa local. Espera-se desenvolver nos estudantes o processo de resoluções criativas para problemas que acontecem no cotidiano das organizações mediante diferentes formas de fazer gestão no âmbito da economia criativa.

Palavras-chave: Organizar, Cotidiano, Criatividade, Contexto Local.

\section{Abstract:}

Context of the case: We use the context of the local creative economy to show the management of two specific organizations. One organization is active in the popular culture segment, and the other organization is acting in the communication and information technology segment. Both organizations demand the resolution of organizational problems relevant to their work context.

Dilemma of the case: We use the concepts of the organizing theory and ordinary management to propose to students that they think of solutions to the problems faced by organizations daily. The solutions to everyday problems are related to the limitations of physical, financial, operational, and technical resources that allow the maintenance and survival of organizations and their managerial demands. 
Case closure: We build the case narrative for teaching from semi-structured interviews, participant observation, and use of public data from the municipal secretariat of the city of Caruaru, in the state of Pernambuco, Brazil. The main idea was to propose a discussion about management made from the daily lives of two organizations that are present in the same context as the local creative economy. We hope to develop in students the process of creative resolutions for problems that happen in the daily lives of organizations through different ways of management within the scope of the creative economy.

KEYWORDS: Organize, Everyday, Creativity, Local Context.

\section{ReSUMEN:}

Contexto del caso: Este caso utiliza el contexto de la economía creativa local y presenta los modos de gestión de dos organizaciones activas en el segmento de la cultura y las tecnologías de la comunicación y la información, ambas demandando la resolución de problemas organizacionales relevantes a su contexto laboral.

Dilema del caso: Utilizamos los conceptos de organización de la teoría de las organizaciones y la gestión ordinaria, proponiendo que los estudiantes piensen en soluciones a los problemas y especificidades que enfrentan las organizaciones en el día a día. Las soluciones a estos problemas cotidianos pueden estar relacionadas con las limitaciones de los recursos físicos, financieros, operativos y técnicos que permiten el mantenimiento y supervivencia de las organizaciones frente a sus demandas gerenciales.

Cierre de caso: La narrativa de caso para la docencia se construyó a partir de entrevistas semiestructuradas, observación participante y uso de datos públicos de la secretaría municipal de la ciudad de Caruaru, Pernambuco, Brasil. Por tanto, la idea central de este caso para la docencia es proponer una discusión sobre la gestión que se hace desde la vida cotidiana de dos organizaciones que operan en diferentes segmentos, pero que están presentes en el mismo contexto que la economía creativa local. Esperamos desarrollar en los estudiantes el proceso de resolución creativa de problemas que ocurren en el día a día de las organizaciones a través de diferentes formas de hacer la gestión en el ámbito de la economía creativa.

Palabras clave: Organizar, Todos los días, Creatividad, Contexto local.

\section{O CASO: A ECONOMIA CRIATIVA CARUARUENSE}

Caruaru, cidade situada no interior do estado de Pernambuco, com aproximadamente 278 mil habitantes, faz uso da criatividade através do artesanato em barro, feiras de rua, confecção de roupas populares, festejos juninos, gastronomia peculiar nordestina etc. como representações características do dinamismo econômico da cidade interiorana, responsável por movimentar a economia. Usar a criatividade para geração de renda e criação de empreendimentos parece ser uma estratégia para lidar com os desafios e as adversidades que marcam o contexto local.

A cidade possui uma economia movimentada, principalmente pela confecção e comercialização de produtos de moda, roupas e acessórios, no qual exerce o papel de liderança no Polo de Confecções, com aproximadamente $30 \%$ de toda produção de confecção do estado de Pernambuco. O São João, festa popular e cultural, também é responsável por colocar Caruaru em destaque nacional. O fluxo dos turistas aumenta durante o mês de junho com o festivo popular. As festas, comidas, artesanatos e o estilo musical do forró estimulam a economia com tradições mantidas até hoje.

Nos dados disponibilizados pela Secretaria de Desenvolvimento Econômico e Economia Criativa (SEDEEC) em 2019, é possível perceber um recorte de 12 segmentos variados de atuação de organizações que trabalham com a criatividade em Caruaru. O quadro 1 mostra os segmentos e a quantidade de trabalhadores ocupados em cada segmento. De maneira geral, são 5.969 pessoas ocupadas com trabalhos criativos em 672 estabelecimentos formais atualmente ativos. Além disso, os segmentos apresentados no quadro 1 sobre a Economia Criativa (EC) representam 13\% do total da economia do município. Essa porcentagem foi informada também pela SEDEEC em outubro de 2020. Segundo a SEDEEC, os dados utilizados para chegar a esse resultado foram extraídos do Portal do Empreendedor e do Cadastro Geral de Empregados e Desempregados (CAGED), disponibilizados no site Contexto Econômico, mantido pela própria secretaria. Neste contexto, é possível perceber a importância da EC para a movimentação econômica, empregabilidade e renda do município de Caruaru. Ressalta-se também que este resultado em porcentagem divulgado pela 
SEDEEC reflete o registro dos profissionais com vínculo de trabalho formal em cada segmento e, portanto, não são levados em consideração os profissionais com vínculo de trabalho informal nessa conta.

Quadro 1 - Segmentação da Economia Criativa em Caruaru (PE)

\begin{tabular}{|l|l|l|}
\hline Segmentos da Economia Criativa & Número de Estabelecimentos Formais & Número de Pessoas Ocupadas \\
\hline Arquitetura e Design & 8 & 36 \\
\hline Artes Performáticas & 15 & 56 \\
\hline Artes Visuais, Plásticas e Artísticas & 9 & 21 \\
\hline Audiovisual & 9 & 25 \\
\hline Edição e Impressão & 9 & 25 \\
\hline Ensino e Cultura & 6 & 101 \\
\hline Informática & 30 & 106 \\
\hline Publicidade e Propaganda & 19 & 46 \\
\hline Entretenimento & 16 & 78 \\
\hline Esporte & 36 & 154 \\
\hline Gastronomia & 433 & 2506 \\
\hline Turismo & 53 & 583 \\
\hline Total & 672 & 5969 \\
\hline
\end{tabular}

Fonte: Elaborado pelos autores com base nos dados disponibilizados pela

SEDEEC. Recuperado de: http://contextoeconomico.caruaru.pe.gov.br/.

Diante desse cenário, Ana, Pedro, Júlia, João e Lucas são pessoas que trabalham com a criatividade e estão incluídas no total de pessoas ocupadas com a economia criativa caruaruense. Ana e Pedro trabalham juntos na área artística e coordenam uma organização de cultura popular, o Teatro de Mamulengos denominado "Pernas de Pau". Com 27 anos de idade, Ana trabalha com arte e criação artística há aproximadamente 12 anos. Já Pedro, com 67 anos de idade, trabalha como artista popular desde 1987 e enxerga no seu trabalho um estilo de vida em defesa da cultura local.

Com Júlia, João e Lucas, o trabalho com a criatividade é um pouco diferente. Eles desenvolvem projetos voltados para área de tecnologia da comunicação e informação (TIC) no Centro Criativo Local (CCL), que é uma organização criada pelo Governo do Estado de Pernambuco para promover a economia criativa na região. Lucas tem 23 anos de idade e está desenvolvendo seu primeiro empreendimento. Ele faz uso das TICs para elaborar um aplicativo que proporciona materiais didático-pedagógicos para pessoas com deficiência visual, na tentativa de melhorar a inclusão social dessas pessoas nos ambientes de ensino e educação.

Júlia é formada em Design, com ênfase em Moda, e está desenvolvendo uma marca autoral, que traz a noção de moda como arte, incentiva a sustentabilidade e o consumo consciente. A ideia central do projeto de Júlia é tornar o consumo de moda autoral mais autêntico, tendo como o público-alvo as pessoas do gênero feminino. Ela mesma desenha os modelos e produz as peças que serão comercializadas através do aplicativo. Já João está no seu terceiro empreendimento: com 45 anos de idade, ele está buscando alternativas de trabalho elaborando o seu projeto de negócio e sua marca. O aplicativo no qual João está trabalhando irá possibilitar aos usuários fazer as compras de supermercados on-line e recebê-las em casa com comodidade.

Os projetos de negócios digitais de Lucas, Júlia e João, e o trabalho artístico e cultural desenvolvido por Ana e Pedro, têm em comum o uso da criatividade e estão inseridos no âmbito da economia criativa local. No entanto, embora partilhem de um contexto comum do uso da criatividade, o cotidiano de trabalho nas organizações em que atuam apresentam peculiaridades e demandas de criação e produção próprias. A gestão a partir do cotidiano é a representação tácita da lida com os problemas do dia a dia. 


\section{O Centro Criativo Local}

Há 4 anos instaurado em Caruaru, o objetivo principal do centro é proporcionar a concepção, desenvolvimento e aplicação de ferramentas, produtos e serviços criativos e inovadores, tendo como base o uso das tecnologias de comunicação e informação (TICs). O Centro Criativo Local (CCL) faz parte do projeto de interiorização do Centro Digital de apoio à Economia Criativa do Estado de Pernambuco, até então atuante apenas na capital do Estado, Recife. O CCL em Caruaru está localizado num espaço dentro do Polo Comercial da Cidade, que é um ambiente de compras responsável pela comercialização das roupas e acessórios de moda produzidos na região.

Com o ambiente dinâmico e interativo, o CCL apresenta um amplo espaço de suporte ao trabalho, contendo tablets, notebooks e computadores de última geração fabricados pela Apple; projetores, cadeiras e mesas coloridas nos espaços de coworking; ambiente de lazer com games e jogos de tabuleiros e espaços para refeições, lanches e convivência para os usuários do local que, geralmente, são os comerciantes e empresários da região. A tônica do local é a liberdade de uso de espaço, com a jornada de trabalho sem restrições de horários ficando a critério dos comerciantes, empresários e empreendedores de acordo com suas necessidades. O corpo administrativo do CCL é responsável pela administração e divulgação dos espaços de reuniões e produtividade, atraindo os comerciantes e empreendedores a otimizarem seus negócios e a construírem espaços de possíveis redes de trabalho entre os empresários locais. $\mathrm{O}$ corpo administrativo também é responsável pela seleção dos projetos de negócios que compõem o programa de incubação de empresas locais financiados pelo governo estadual.

A seleção dos projetos de negócios para o programa de incubação é pública, feita por meio de edital desenvolvido pelo corpo técnico-administrativo do CCL e divulgada pelo núcleo de comunicação do centro para toda a população. Como estrutura, o CCL tem três núcleos funcionais centrais de atividades: atividades de criação com uso dos laboratórios de design gráfico, de produto e de moda, modelagem 3D, desenvolvimento de games e animação; as atividades de prototipação com a utilização dos laboratórios de digitalização e impressão 3D, produção gráfica e vestuário; as atividades voltadas ao editorial de moda com estúdios de fotografia e vídeo, mixagem e pós-produção audiovisual. Nesses laboratórios, Júlia, Lucas e João desenvolvem suas atividades diárias na elaboração de seus aplicativos e empreendimento. Eles estão passando pelo programa de incubação, que é a forma de organização das atividades por fases de aprimoramento de seus projetos de negócios. O programa de incubação acontece em 4 fases passíveis de serem visualizadas com maior detalhe no quadro 2 a seguir.

Quadro 2 - Descrição do Processo de Incubação

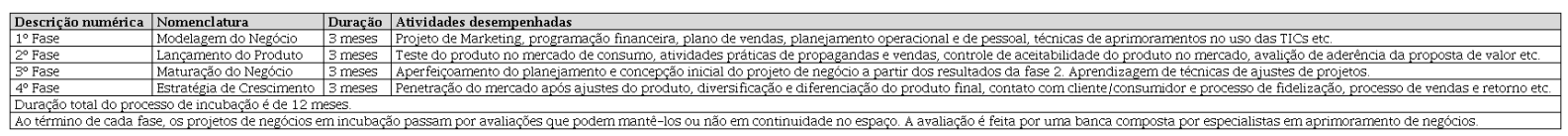

Fonte: Elaborado pelos autores.

Em cada fase do programa de incubação existem consultorias que servem para aprimorar os negócios que estão sendo desenvolvidos pelos empreendedores. As consultorias são organizadas e programadas pelo setor administrativo do CCL, de acordo com o cronograma de atividades de aprimoramento dos projetos. No geral, as consultorias visam a melhoria dos processos específicos que acontecem em cada fase do programa. Por exemplo, são prestadas consultorias de plano de marketing e identidade visual que servem de suporte 
de capacitação dos empreendedores e seus projetos. No setor administrativo da CCL trabalha Bruno Cavalcante, empresário e coordenador geral do programa de incubação. Bruno comentou um pouco sobre as fases do programa e lembra dos critérios que precisam ser atingidos pelos empreendedores dos projetos de negócios. Os recortes da fala são expostos em sequência.

São quatro módulos ao total. O primeiro módulo, nos três primeiros meses, a gente trabalha a questão da modelagem do negócio que é ver ... fazer ferramentas para testar possibilidades e ver qual é a estratégia melhor para as empresas. Então, no final desses três primeiros meses aí o ideal é os empreendedores estarem com o modelo de negócio mais completo e começar a aplicar. A partir disso começa o segundo módulo que é o lançamento do produto ou serviço. É aí que de fato os empreendedores têm que começar a testar, jogar para o mercado. São três meses também para eles validarem a ideia de negócio que eles tiveram lá atrás no começo do projeto. Um terceiro módulo é a maturação que é que você vai ver em cima do que você validou o que é que o mercado quer, o que é que o mercado não quer, o que é que está fazendo certo, e o que é que está fazendo errado. Para talvez os empreendedores mudarem as suas estratégias. Então, é a fase que chamamos de maturação do negócio. Por fim, nos últimos três meses é a fase de estratégia de crescimento que é observar o que foi aprendido, o que foi validado, o que deu certo e o que não deu pra poder pensar e levar mais pra frente, porque ao final da incubadora, teoricamente, a empresa está mais preparada pro mercado. Então, essa última fase é justamente focada nisso, em deixar as empresas andar com os próprios pés (entrevista com Bruno).

Bruno ainda ressalta que:

Tem uma avaliação que analisa cinco aspectos: o aspecto empreendedor que é justamente a equipe, a gestão do negócio propriamente dito e como está sendo a organização da empresa. $\mathrm{O}$ aspecto do mercado que é analisar se realmente existe mercado para aquele negócio. A gestão da tecnologia que é ver quais são as tecnologias que estão sendo aplicadas naquele negócio. E o aspecto do capital que são os resultados financeiros que a empresa está tendo nos três meses. Então, os avaliadores analisam esses cinco aspectos e dão uma nota de zero a dez e tem um requisito mínimo de ter sete, média sete para poder continuar no processo (entrevista com Bruno).

Com a proximidade da banca de avaliação da primeira fase do processo de incubação, em um chat numa rede social, Júlia, angustiada, conversa com Lucas e João sobre os problemas que vem enfrentando corriqueiramente na concepção de seu negócio. Lucas e João estão há mais tempo no programa de incubação, próximos de terminar a quarta fase. As imagens na sequência expóem o diálogo que ocorreu entre eles. 
Administração Pública e Gestão Social, 2021, vol. 13, núm. 3, Julio-SePtiembre, ISSN: 2175-5787

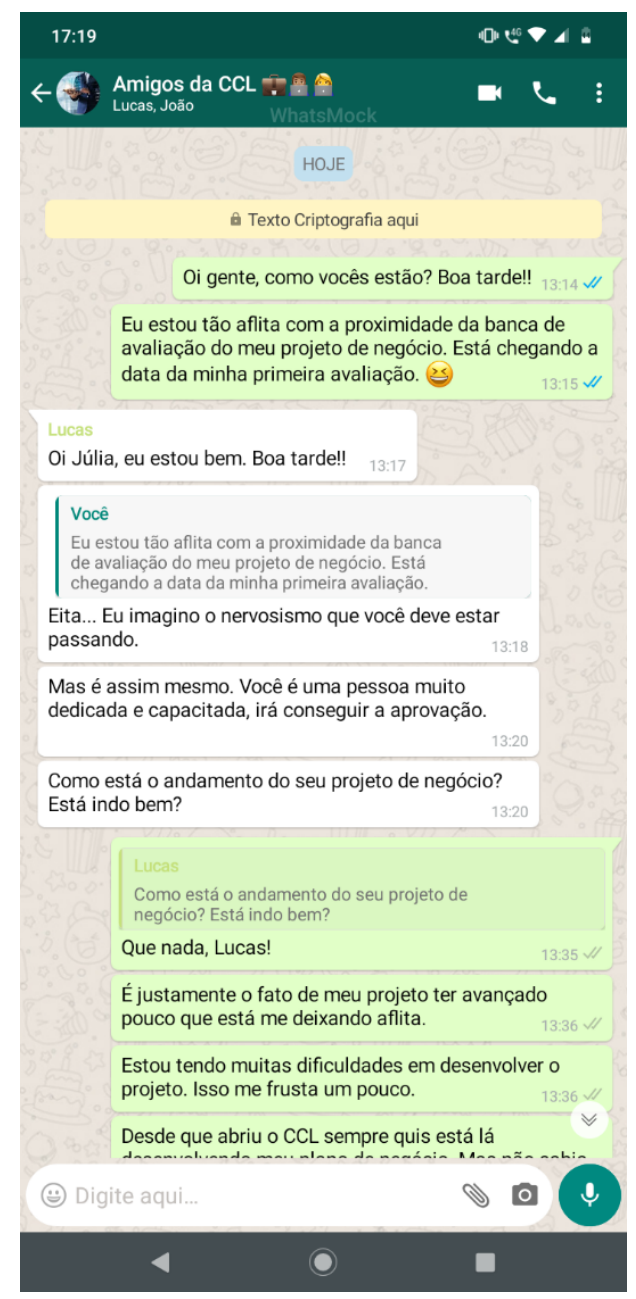

Figura 1 - Conversa em chat na internet Fonte: Elaborada pelos autores. 
Ítalo da Silva, et al. Organizing e Gestão Ordinária na Economia Criativa local

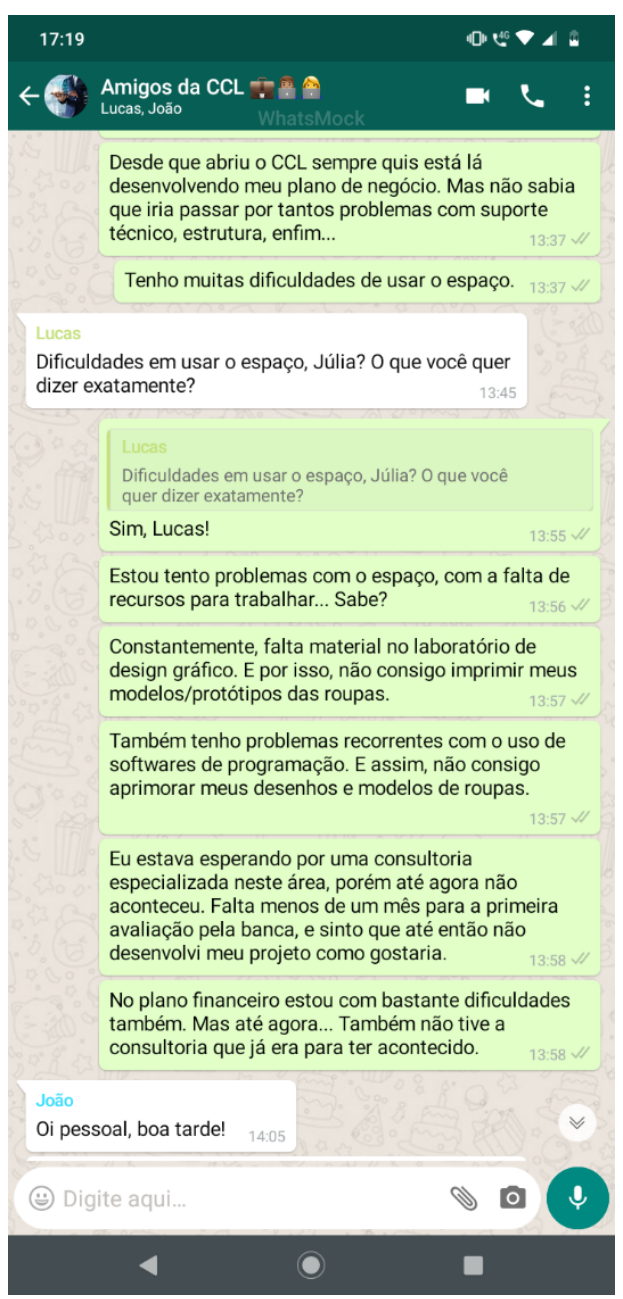

Figura 2 - Conversa em chat na internet Fonte: Elaborada pelos autores. 
Administração Pública e Gestão Social, 2021, vol. 13, núm. 3, Julio-SePtiembre, ISSN: 2175-5787

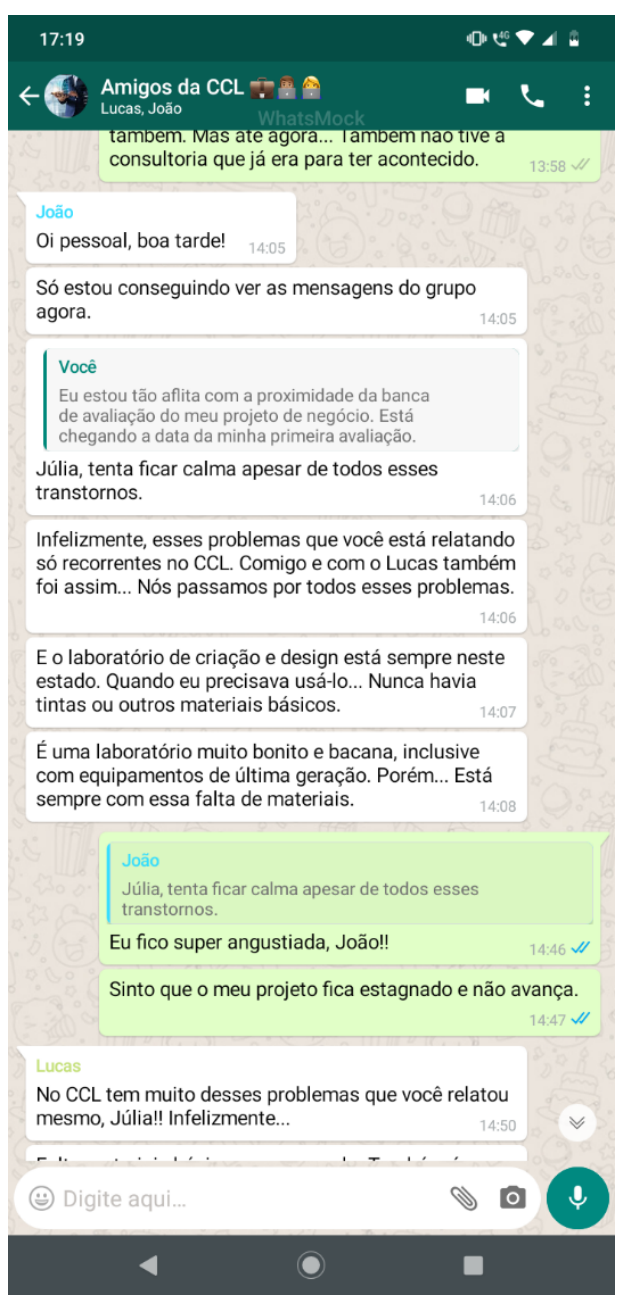

Figura 3 - Conversa em chat na internet

Fonte: Elaborada pelos autores. 
Ítalo da Silva, et al. Organizing e Gestão Ordinária na Economia Criativa local

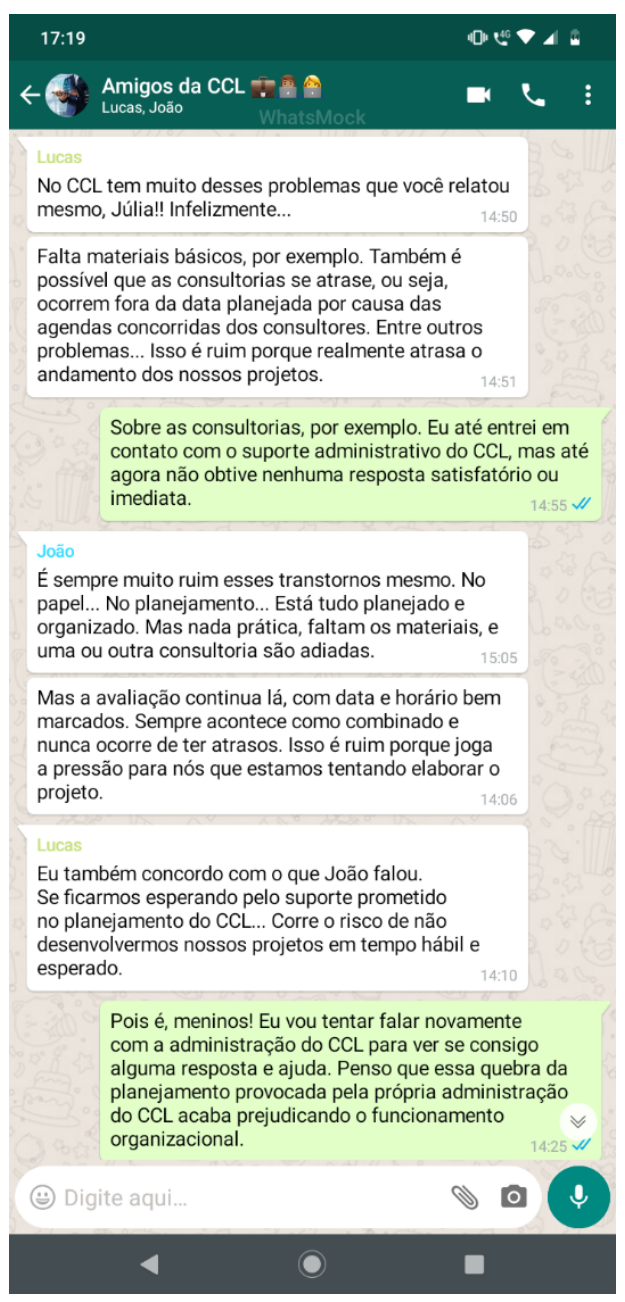

Figura 4 - Conversa em chat na internet Fonte: Elaborado pelos autores. 


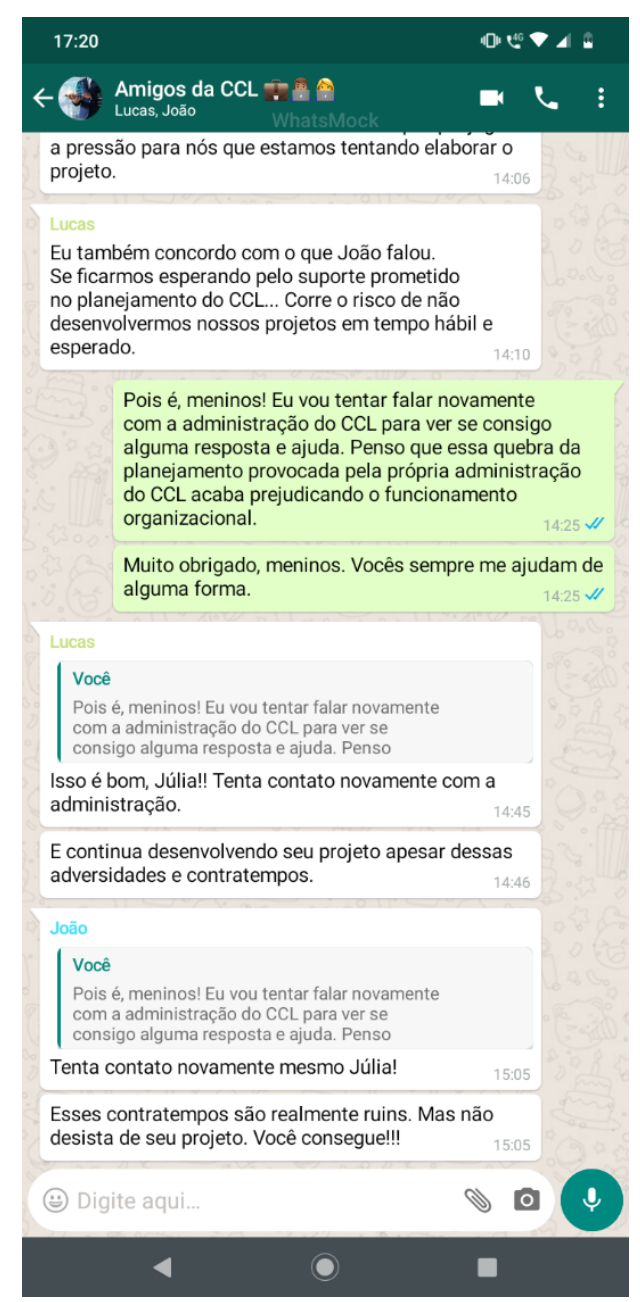

Figura 5 -Conversa em chat na internet Fonte: Elaborada pelos autores.

No outro dia, após a conversa, Júlia entrou em contato com os responsáveis pela administração do CCL que gerenciam as fases do programa de incubação. Apreensiva pelo andamento do projeto, questionou a administração sobre a falta de consultorias para uso dos softwares no laboratório de design gráfico e sobre o auxílio técnico previsto para a formulação do plano financeiro para o projeto. Em resposta, a administração comunicou que as consultorias não puderam acontecer ainda por falta de datas nas agendas dos consultores e que as consultorias iriam ocorrer uma semana antes da banca de avaliação da primeira fase, servindo apenas para correções pontuais do projeto. A administração lamentou as mudanças que aconteceram no cronograma planejado devido aos imprevistos, mas notificou os empreendedores da possibilidade de uso do espaço oferecido pelo CCL por terceiros que auxiliassem os candidatos com projetos de negócios em andamento sob responsabilidade do titular de cada projeto.

Quando Júlia recebeu a notificação oficial da administração, lamentou a situação e percebeu que estava com problemas graves de planejamento básico no seu projeto e que as consultorias iriam ser necessárias para saná-los. Ainda falta Júlia desenvolver toda a identidade visual do seu projeto, além de desenvolver o projeto financeiro que permita o amadurecimento dos projetos nas fases posteriores do programa de incubação. Com menos de 15 dias para a primeira avaliação do projeto, Júlia se vê perdida com falta de recursos físicos e sem o apoio institucional esperado pela administração do CLL, e teme por talvez não conseguir entregar as etapas de projeto solicitado a tempo, sendo desclassificada do programa. 


\section{O Teatro de Mamulengos "Pernas de Pau"}

A gente não tem muita preocupação com planejamento, é tudo momento, é tudo prática... Você chega agora e já começa a trabalhar. Para fazer boneco? É agora! As coisas por aqui são feitas a favor das circunstâncias.... Aqui a gente vende pirulito, pipoca, algodão doce, refrigerante. Arte a gente repassa, não se vende... Veja, o importante é você estar praticando algo que está servindo para você no universo e não só o dinheiro. As pessoas nos veem como loucos. Essas pessoas que não descobriram ainda o valor da cultura popular (entrevista com Pedro).

Este é o modo de organização presente no Teatro de Mamulengos "Pernas de Pau”, explicado por Pedro. As atividades no teatro começam logo cedo. Não são nem 6 horas da manhã e Pedro está abrindo o teatro para começar os trabalhos com processos de produção dos bonecos de mamulengos, feitos de maneira artesanal. Não há um horário de trabalho padrão definido. As atividades são desenvolvidas durante o dia a partir do surgimento das demandas. Sem planejamento prévio, as atividades vão acontecendo mediante as necessidades práticas da organização. São produzidos dois tipos de bonecos, comumente feitos à base de papel machê ou de madeira. O papel machê é uma mistura de papel higiênico, água, sabão, detergente, bofo, trigo e maisena, para fazer a massa a ser modelada. Já o boneco confeccionado em madeira é produzido à base de umburana, também conhecida como cumaru-das-caatingas, madeira típica da região (ver imagens abaixo).

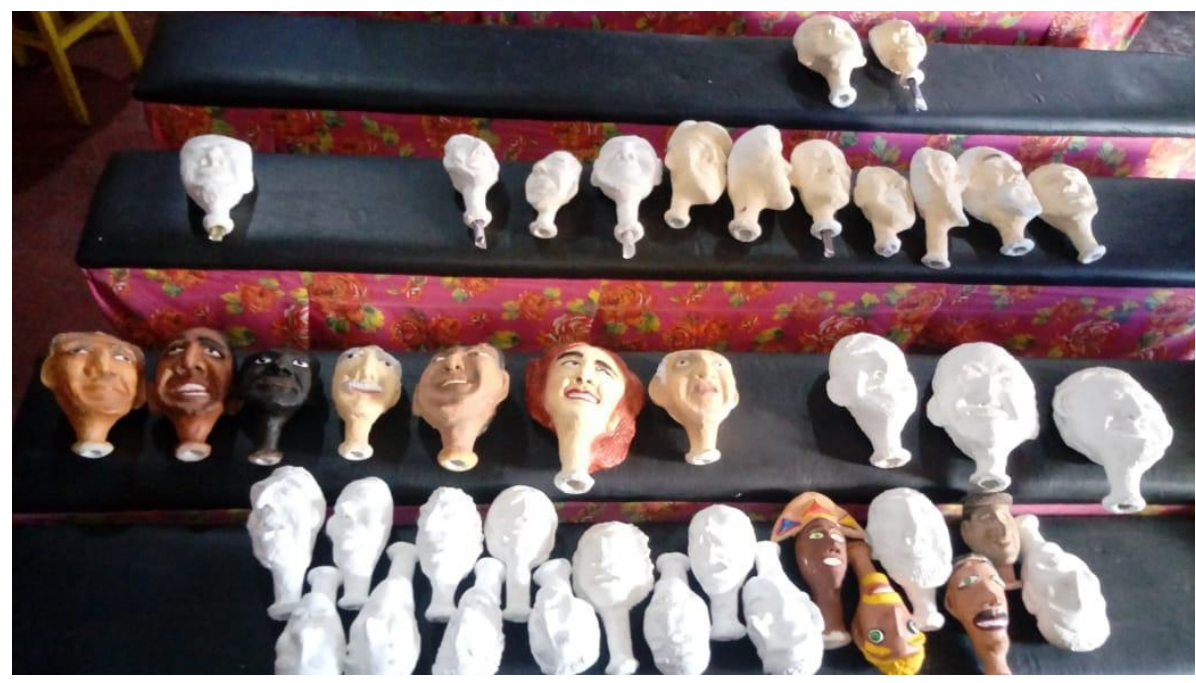

Figura 6 -Bonecos de Mamulengos em produção Fonte: Elaborada pelos autores. 


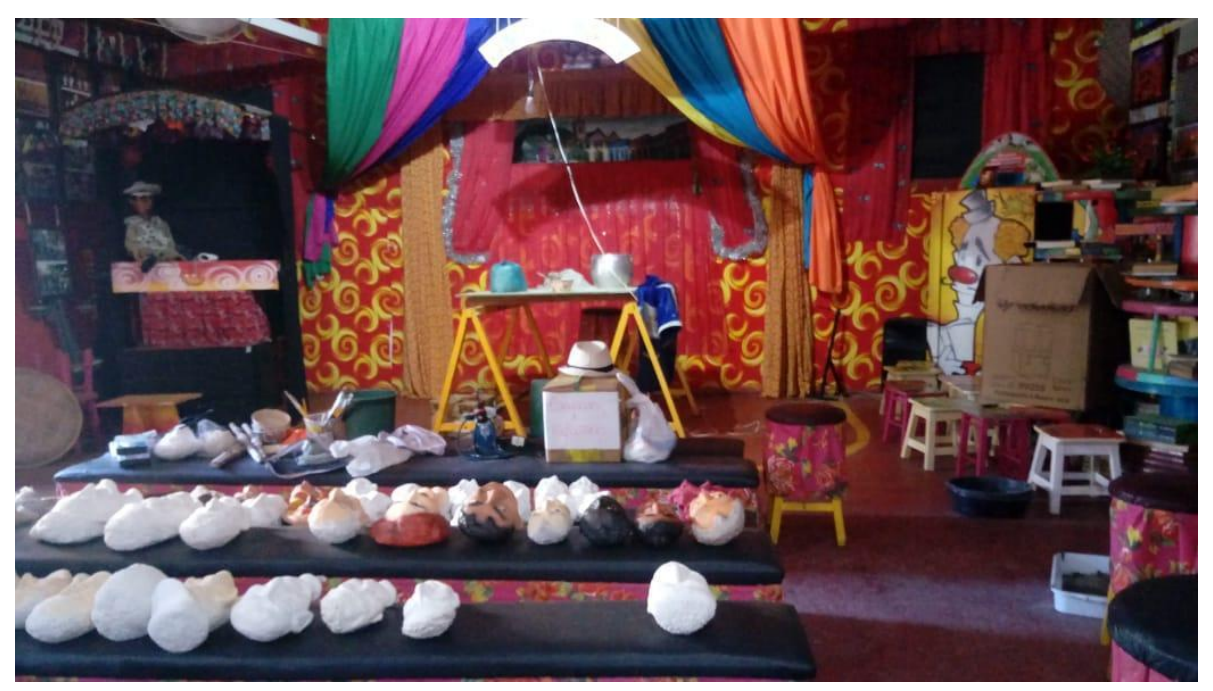

Figura 7 -Teatro de Mamulengos

Fonte: Elaborada pelos autores.

A organização comandada por Pedro fica localizada na antiga estação ferroviária da cidade, em um espaço público cedido pelo governo municipal. Outras organizações de cultura popular ocupam o espaço cedido, como as expressões culturais da banda de pífano, do boi bumbá, do cordel e da capoeira. São vários galpões de madeiras que foram construídos pelos próprios "mestres da cultura", como são conhecidas as pessoas que comandam tais organizações e fazem acontecer a cultura popular que apresentam. É um local em constante disputa entre poder público e os fazedores de cultura. O Governo Municipal deslocou, recentemente, os galpões de cultura em que as organizações ficavam na estação para outro local mais distante do centro da cidade, com a pretensão de revitalizar o espaço público central da cidade, o que impactou na visibilidade das organizações de cultura para o público em geral.

O teatro de mamulengos "Pernas de Pau" mantém-se financeiramente a partir das apresentações realizadas toda semana. A apresentação simboliza uma mistura entre técnica, ensaio, performance, coordenação, histórias, fantasias e humor. Aos domingos, a partir das $17 \mathrm{~h}$, manipuladores de bonecos, mediadores de palco e contadores de história reúnem-se para apresentações. As apresentações são pensadas para as crianças, mas são abertas ao público em geral, não tendo uma faixa etária definida.

Para assistir as apresentações, são cobrados cinco reais dos responsáveis pelas crianças. Esse valor é cobrado em troca de algodão doce e pipoca, que as crianças recebem assim que entram no teatro. Dentro do teatro, há uma cantina que vende comidas e bebidas. Parte do dinheiro arrecadado com a venda dos lanches é repartido entre os artistas que trabalham nas apresentações, e outra parte do dinheiro é usada na manutenção do teatro.

Quando tem apresentação, nos domingos, aí que eles também dão sua colaboração, que nós não cobramos nada. Além de não cobrar nada, se paga aqui uma pipoca e um algodão doce, 5 reais. E como domingo, deu 140 reais, aí tinha doze pessoas envolvidas. Ficou 10 reais para cada um. E assim a gente vai, e recebo, sim, apoio da prefeitura municipal como esse espaço é administrado por ela, como no São João estou aqui. Como os eventos eles me convidam e me pagam pelo meu trabalho (entrevista com Pedro sobre a última apresentação que ocorreu no teatro).

A limitação de recursos financeiros dificulta a manutenção das atividades culturais do teatro.

Outra fonte de renda para o teatro são as apresentações privadas, nas quais são contratados para animar festas infantis, eventos culturais e apresentações em escolas. Os meios de divulgação principais das apresentações e trabalhos realizados pela organização são as redes sociais e a comunicação via rádio e televisão local, mas não há preocupação extensiva e intensiva com a divulgação dos trabalhos em que, por vezes, ocorre de as pessoas não comparecerem nas apresentações, resultando em apresentações com pouquíssimo público. Embora exista a procura do mercado em comprar os bonecos de mamulengos produzidos pelo teatro, até 
então o posicionamento da organização é da não comercialização dos bonecos. Pedro acredita que a arte popular deve ser repassada, e não vendida.

Se o senhor trouxer uma carreta aqui de dinheiro, desse tal de euros que é mais caro, para mim fazer aqui um boneco, eu mando dá um rezinho, porque eu não preciso de dinheiro. Porque quando eu morrer não vou levar. Olha, eu quero alimento e quero paz e saúde. E quero a espiritualidade da criança para com o adulto para transformar esse mundo que tá podre a cada dia (entrevista com Pedro).

Ana é professora e ensina a arte de produção e apresentação dos bonecos de mamulengos à comunidade através de oficinas que são realizadas semanalmente. As oficinas são gratuitas e abertas a todos os públicos. Só é necessário que os participantes tragam os materiais que vão usar na concepção de seus bonecos, uma vez que os recursos do teatro são escassos e não teria como financiar todo o material. Ainda assim, existe uma preocupação de reutilizar e reciclar os materiais de maneira criativa. Tecidos, garrafas plásticas, tintas, pincéis, entre outros materiais, são compartilhados entre os praticantes no momento de confecção de bonecos para reutilização econômica dos materiais.

Apesar do posicionamento de Pedro de não comercializar os bonecos produzidos pelo teatro e oferecimento gratuito das oficinas de produção de bonecos a comunidade, o teatro apresenta custos de manutenção da estrutura física e da geração de renda para os profissionais que trabalham com as apresentações. A dificuldade na captação de recursos financeiros é um problema constante que atinge diretamente a sobrevivência do teatro e, por consequência, a cultura popular de mamulengos. Repensar a forma de organização peculiar da administração do teatro parece ser necessária, mas a filosofia existente e o modus operandi na gestão do teatro podem ser barreiras que dificultam a melhoria da comercialização dos produtos e serviços ofertados, que precisam ser pensadas para a sobrevivência do teatro.

\section{Dilema do Caso}

Diante do contexto da economia criativa local de Caruaru (PE), é possível perceber que ambas as organizações, tanto o Teatro de Mamulengos "Pernas de Pau" como a Centro Criativo Local (CCL), apresentam diferentes maneira de fazer a gestão no seu dia a dia, demandando resoluções de problemas organizacionais inerentes ao seu contexto de trabalho. Sendo assim, a discussão central a ser tratada a partir dos casos apresentados são: como Júlia pode superar as limitações de recursos físicos e operacionais para continuar desenvolvendo seu projeto de negócio no modelo de gestão característico do CCL? Como Pedro e Ana podem garantir a sobrevivência econômica e simbólica da cultura popular que representam através da organização do Teatro de Mamulengos, considerando a filosofia peculiar de gestão inerente ao seu trabalho?

\section{Notas de Ensino}

\subsection{Objetivos educacionais}

Objetivo central deste caso para ensino é propor uma discussão sobre a gestão feita a partir do cotidiano de duas organizações com atuações em segmentos diferentes, mas que estão presentes no mesmo contexto da economia criativa. É indicado que os estudantes pensem em soluções para os problemas e especificidades enfrentados pelas organizações em seu dia a dia a partir da noção de organizing, como avanço teórico de teoria das organizações, o conceito de gestão ordinária e a noção de economia criativa como contexto local de administração das organizações. Indica-se que o caso seja direcionado para estudantes da graduação em Administração nas disciplinas como Introdução à Administração e Teoria Geral da Administração, mostrando o aprimoramento da teoria organizacional em contextos específicos de análise. $\mathrm{O}$ caso também 
pode ser aplicado em disciplinas correlacionadas, como Microanálise das Organizações, Gestão de Processos e Processo Decisório.

\subsection{Fonte de informações}

A narrativa e contextualização foram construídas baseadas em informações coletadas para atender o objetivo de uma primeira pesquisa intitulada "Organizações Enquanto Práticas: uma Análise Narrativa no Contexto da Economia Criativa Local”. Desse modo, a partir das informaçóes coletadas que alimentaram a pesquisa acima mencionada, este caso para ensino foi pensado com adaptações do contexto empírico real da pesquisa.

As informações foram coletadas no Centro Criativo Local (CCL) e no Teatro de Mamulengos "Pernas de Pau", por meio de: (1) observação participante, (2) entrevistas semiestruturadas e (3) informações coletadas diretamente na Secretaria de Desenvolvimento Econômico e Economia Criativa de Caruaru (SEDEC). A coleta de informações ocorreu entre os meses de fevereiro e abril de 2019. Desta forma, as técnicas de coleta utilizadas configuram uma triangulação das informações. A triangulação viabiliza a confiabilidade e validade das informações uma vez que elas foram cruzadas e confrontadas (Martins \& Theóphilo, 2009; Zappellini $\&$ Feuerschütte, 2015). As entrevistas foram gravadas e transcritas, e as observações foram anotadas em um diário de campo. A fim de preservar os entrevistados e as organizações, optou-se por adotar nomes fictícios.

\subsection{Aspectos pedagógicos}

O caso para ensino aqui proposto tem o papel de relacionar a discussão teórica com a prática da administração, estimulando os estudantes a refletirem sobre dilemas presentes no dia a dia das organizações. Este exercício põe os estudantes como protagonistas do aprendizado, possibilita que coloquem em prática o que aprenderam em aula, transmitam esse aprendizado, desenvolvam o processo de tomada de decisão e soluções de maneira criativa (Roesch, 2007; Alberto \& Silva, 2018).

\subsection{Aplicação do caso}

Aconselha-se que o caso seja aplicado após a explicação dos temas teóricos abordados, como a teoria de organizing e gestão ordinária. O professor pode entregar o caso na sequência da aula expositiva ou antes da entrega do caso fazer uma breve introdução sobre os temas acima mencionados. Após elucidar sobre os temas trabalhados no caso, o professor pode distribuir o caso e deve orientar que os estudantes façam a leitura atenta do caso individualmente (Roesch, 2007) e respondam às questões propostas. Além disso, o professor pode pedir aos alunos para trazerem as respostas que foram individualmente elaboradas na aula seguinte, ressaltando que os estudantes não devem acessar as notas de ensino.

Posteriormente, na aula reservada para os estudantes trazerem suas resoluções recomenda-se que o professor solicite aos estudantes que formem grupos de até cinco pessoas, uma vez que trabalhar com grupos menores possibilita maior participação de todos, e que o grupo converse sobre as soluções que haviam elaborado antes individualmente, de modo que o grupo, de maneira participativa e democrática, entre em acordo sobre uma única resposta que os representem. Após esta etapa, sugere-se que o professor solicite à turma que forme um círculo na sala de aula, com o objetivo de que todos possam assistir as apresentações. Os grupos devem ser orientados a apresentar as soluções encontradas para as questóes do caso de forma sucinta. Após as apresentações, o professor pode questionar os estudantes suas percepções sobre o caso e, por fim, o professor pode abordar qual o objetivo do caso, destacando os principais aspectos. Sugere-se que seja destinado para o desenvolvimento de todas as etapas de discussão e apresentação do caso, aproximadamente, 2 horas e 20 minutos (ver quadro 3). 
Quadro 3 - Recomendações de aplicação do caso

\begin{tabular}{|c|c|c|}
\hline $\begin{array}{l}\text { Primeiro } \\
\text { Momento }\end{array}$ & Orientações de Tratamento do Caso & Tempo \\
\hline 1 & Fazer leitura individual em casa. & \multirow{3}{*}{$\begin{array}{l}10 \\
\text { minutos }\end{array}$} \\
\hline 2 & Responder o caso e trazer as respostas na próxima aula. & \\
\hline 3 & Recomendação para não acessar as notas de ensino. & \\
\hline $\begin{array}{l}\text { Segundo } \\
\text { Momento }\end{array}$ & Discussão do Caso & Tempo \\
\hline 4 & Formar grupos de até cinco estudantes. & \multirow{2}{*}{$\begin{array}{l}40 \\
\text { minutos }\end{array}$} \\
\hline 5 & $\begin{array}{l}\text { Orientar que os grupos discutam e cheguem a uma } \\
\text { conclusão coletiva. }\end{array}$ & \\
\hline 6 & Pedir para formar um círculo na sala de aula. & \multirow{2}{*}{$\begin{array}{l}60 \\
\text { minutos }\end{array}$} \\
\hline 7 & $\begin{array}{l}\text { Orientar os grupos para a apresentação das resoluções do } \\
\text { caso. }\end{array}$ & \\
\hline 8 & Indagar aos estudantes suas impressões do caso. & $\begin{array}{l}15 \\
\text { minutos }\end{array}$ \\
\hline 9 & Explanar o objetivo geral do caso. & $\begin{array}{l}15 \\
\text { minutos }\end{array}$ \\
\hline
\end{tabular}

Fonte: Elaborado pelos autores.

\subsection{Questôes para discussão}

1. Dentro do contexto da economia criativa local em Caruaru (PE), qual a importância do Centro Criativo Local (CCL) e do Teatro de Mamulengos "Pernas de Pau" como organizações, tendo em vista o estímulo do Governo do Estado a nível municipal?

2. Caracterize a gestão do Centro Criativo Local (CCL) e do Teatro de Mamulengos "Pernas de Pau", ressaltando os pontos de similaridades e divergência entre elas.

3. Diante do modelo característico de gestão presente no Centro Criativo Local e a cobrança pela entrega de resultados feita aos empreendedores como requisitos do programa de incubação, como a personagem Júlia pode dar continuidade ao seu projeto de negócios a partir de suas demandas?

4. O Teatro de Mamulengos "Pernas de Pau" apresenta um modelo de gestão característico ao seu âmbito de atuação. O desafio principal para os personagens Pedro e Ana é manter a sobrevivência da organização e as apresentações culturais que realizam. A partir disso, detalhe as possibilidades que permitam a manutenção do funcionamento da organização.

\subsection{Guia teórico para discussão}

Para auxiliar o professor na condução e discussão do caso, estruturou-se um guia teórico de apoio à discussão da seguinte maneira: na primeira subseção discute as distinções conceituais sobre Economia Criativa como contexto mais amplo de análise das organizações, no qual é possível ser visualizada a resposta sugerida para a questão de número 1 . Na segunda subseção, foram explanados os conceitos de organizing como avanço da teoria das organizações e Gestão Ordinária, em que é possível identificar as resoluções indicadas para as questões 2,3 e 4 .

\subsubsection{Economia criativa: questôes conceituais}

Não existe consenso na literatura sobre a definição de economia criativa. O que existe de fato são diferentes maneiras de enxergar como a criatividade, ou inventividade das pessoas, pode ser usada na geração de serviços 
e (ou) produtos, bem como de sua proposta de valor. Ao estudar os diferentes conceitos e definições na literatura, é possível perceber a dificuldade em distinguir e demarcar termos conceituais como "indústrias culturais", "indústrias criativas" e "economia criativa”. A importância de diferenciar tais conceitos se dá na necessidade de restringir a análise contextual em que as organizações operam.

Os relatórios gerados pela Conferência das Nações Unidas sobre Comércio e Desenvolvimento (UNCTAD) dão pistas de como diversos países no mundo estão entendendo a economia criativa e como os governos estão implementando políticas públicas para essa área. No contexto da economia criativa em Caruaru (PE), pode-se perceber uma forte interferência estatal, pois o Governo Estadual passou a estimular o desenvolvimento de políticas públicas de economia criativa a nível municipal, ora no deslocamento das organizaçóes de cultura do centro da cidade como ocorreu no caso do Teatro de Mamulengos, ora instaurando o Centro Criativo Local para incentivar a elaboração de projetos de negócios locais baseados nas TICs. A noção de criatividade como capacidade inventiva pode ser compreendida a partir da concepção e geração de ideias, assim como a transformação destas ideias em algo tangível. A UNCTAD (2008; 2010; 2013) compreende que importa perceber como as ideias são processadas, conectadas e transformadas em algo capaz de gerar valor - não só, mas sobretudo econômico - para a comunidade em que se insere, ou ainda, “a criatividade é o uso de ideias para produzir novas ideias" (UNCTAD, 2010, p. 4). Ao longo do tempo, desde o avanço das indústrias culturais ao discernimento da economia criativa, pode-se perceber que o conhecimento e a capacidade intelectual das pessoas são usados como pontos de partida na criação de produtos e (ou) serviços criativos (Kon, 2016).

A indústria cultural foi um termo que apareceu após a Segunda Guerra Mundial e foi utilizado por estudiosos da Escola de Frankfurt como Theodor Adorno (1903-1969) e Max Horkheimer (1895-1973) (UNCTAD, 2010; 2013). Em um viés mais crítico, o termo surge como forma de denotar as ações das indústrias que massificavam os bens culturais e o entretenimento mediante espetacularização da cultura. Para Machado (2009), a indústria cultural é um conceito analítico da sociedade capitalista, pois através dele é possível perceber como a cultura é transformada em entretenimento de massa, resultando em uma mercadoria para o consumo. Começou-se, então, a pensar como agregar valor aos produtos e serviços derivados da cultura para geração de riqueza.

A ideia de indústria criativa é posta de início num relatório gerado pelo governo australiano, em 1994, intitulado "Creative Nation", embora o termo apresente variações entre os países (UNCTAD, 2010; Kon, 2016). Assim, a indústria criativa aumenta o campo de atividades para além de atividades atreladas a indústria cultural, alcançando mais áreas de produção que não só a cultura. $O$ conceito de "indústrias criativas que vem se desenvolvendo desde então tem ampliado o escopo das indústrias culturais para além das artes, marcando uma mudança de abordagem às atividades comerciais" (UNCTAD, 2010, p. 6). Desse modo, as indústrias culturais passam a fazer parte de um subconjunto das indústrias criativas, ao passo que os produtos e (ou) serviços criativos impulsionam o crescimento através da criação de valor como elementos-chave do sistema econômico baseado na criatividade (UNCTAD, 2010, 2013; Britto, 2016; Kon, 2016).

Como já apontado anteriormente, não há um consenso sobre um conceito de economia criativa. Isto porque, acredita-se que tal conceito se encontra ainda em elaboração. John Howkins, em seu livro intitulado "The creative economy: how people make money from ideas", de 2001, é um dos primeiros a sistematizar um conceito de economia criativa (Kon, 2016). Indo além, a UNCTAD (2008; 2010; 2013) entende que economia criativa é um conceito em evolução baseado em ativos criativos que potencializa o crescimento econômico, a geração de emprego e renda atrelado a questóes sociais, culturais e econômicas, e tem papel central na economia e na articulação entre criação e mercado.

A figura 8 sintetiza os principais pontos que estão por trás de cada conceito em progressão temporal a partir da literatura. É possível perceber que os conceitos não são excludentes; o que se observa, de fato, é que o conceito de economia criativa abarca o entendimento conceitual de indústria criativa que, por sua vez, alcança o conceito de indústria cultural, criando traços característicos que são contínuos e interligados. Neste sentido, 
um conceito é ponto de especificidade em um outro. Assim, tanto as indústrias culturais quanto as indústrias criativas, por exemplo, são segmentos no contexto da economia criativa. Esse entendimento permite situar as organizações apresentadas no caso como atuantes em seguimentos importantes da economia criativa em Caruaru (PE) a partir da análise do quadro 1.

Britto (2016) argumenta que a economia criativa pode ser compreendida a partir de processos colaborativos entre criatividade, tecnologia e negócios, que emergem do núcleo de criação das pessoas como expressões estéticas do trabalho. Nesta mesma linha, Kon (2016) destaca que a economia criativa é a economia que envolve também o intangível, o simbólico, que tem como base pessoas para produzir bens e serviços criativos. Em outras palavras, seja uma expressão cultural local, seja a elaboração de um software, ou até mesmo produtos da moda em roupas, são setores que atuam dentro do contexto da economia criativa, que transforma uma ideia em materialidade de produto e (ou) serviço, baseado na inventividade das pessoas. Essas características parecem orientar a análise da economia criativa a nível local.

Um estudo desenvolvido recentemente pela Federação das Indústrias do Estado do Rio de Janeiro (FIRJAN), alinhado ao entendimento de economia criativa sob a ótica das indústrias criativas, mostra como estas indústrias estão mapeadas e postas por todo o Brasil (ver FIRJAN, 2019). A metodologia dessa pesquisa adota como parâmetro 13 segmentos criativos divididos em 4 grandes áreas criativas que foram delimitadas mediante afinidade entre os segmentos. Assim, as áreas e seus segmentos são: (1) consumo (design, arquitetura, moda e publicidade \& marketing); (2) mídias (editorial e audiovisual); (3) cultura (patrimônio e artes, música, artes cênicas e expressões culturais); e (4) tecnologia (P\&D, biotecnologia e TIC) (FIRJAN, 2019). Esta segmentação mostra o quão grande é o escopo de organizações que podem atuar em variados segmentos da economia criativa em que pode ser melhor demostrado no quadro 4.

\begin{tabular}{|c|c|c|}
\hline Indústria Cultural & Industria Criativa & Economia Criativa \\
\hline $\begin{array}{c}\text {-Surgimento do termo } \\
\text { no período pós-guerra. } \\
\text { •Crítica radical ao } \\
\text { entretenimento de } \\
\text { massa. } \\
\text {-Referência a Theodor } \\
\text { Adorno e Max } \\
\text { Horkheimer. } \\
\text {-Produtos e serviços } \\
\text { culturais. } \\
\text { •Combinação } \\
\text { conflituosa entre } \\
\text { cultura e economia. }\end{array}$ & $\begin{array}{l}\text { •Termo utilizado no } \\
\text { relatório "Creative } \\
\text { Nation" (1994), pelo } \\
\text { governo australiano. } \\
\text { •Ampliação do escopo } \\
\text { de atuação para além da } \\
\text { indústria cultural das } \\
\text { artes. } \\
\text { •Indústria cultural como } \\
\text { subconjunto da } \\
\text { indústria criativa. } \\
\text { •Setores artísticos, de } \\
\text { serviços e industriais. } \\
\text { •Produtos e serviços } \\
\text { criativos. }\end{array}$ & $\begin{array}{c}\text { • Conceito cunhado de } \\
\text { início pelo pesquisador } \\
\text { inglês John Howkins } \\
\text { em } 2001 . \\
\text { • Conceito mais amplo } \\
\text { que engloba os setores } \\
\text { de indústrias culturais e } \\
\text { criativas. } \\
\text { • Uso de ideias para } \\
\text { produzir novas ideias. } \\
\text { •Baseado na capacidade } \\
\text { intelecual para geração } \\
\text { de produtos e/ou } \\
\text { serviços. } \\
\text { •Produtos e serviços } \\
\text { criativos. }\end{array}$ \\
\hline
\end{tabular}

Figura 8 - Delimitações conceituais

Fonte: Elaborado pelos autores baseado em UNCTAD (2008, 2010, 2013), Britto (2016) e Kon (2016).

O posicionamento que orienta bem a resolução da questão 1 e ajuda na discussão das questões subsequentes é perceber que a economia criativa compreende a criatividade e inventividade das pessoas como centrais para o desenvolvimento econômico, social, cultural e sustentável da sociedade. Essa criatividade impacta na geração de produtos e (ou) serviços criativos que oportunizem trabalho, renda e riqueza. É entender também que o ciclo de criação, produção, distribuição e consumo das propostas de valor destes produtos e (ou) serviços ligados à dimensão simbólica dos trabalhos das pessoas, sejam com as artes, sejam com a tecnologia, 
ou até mesmo com a moda, isto é, diferentes maneiras de usar a criatividade - não distante de seu contexto (UNCTAD, 2013; Kon, 2016).

Sendo assim, sugere-se como resolução para $1^{\text {a }}$ questão que o professor destaque as informações trazidas pelo quadro 1. A partir dele, pode-se pontuar que os segmentos das organizações do caso são de cultura popular e TICs, que, assim como outros segmentos da economia criativa (como, por exemplo, a gastronomia e o turismo), são responsáveis pela movimentação econômica e empregabilidade do município conforme dados do SEDEEC (2019). Neste caso, pelo relatório da Firjan (2019), o CCL se encaixa no segmento de tecnologias (TIC) e o teatro "Pernas de Pau", no segmento de cultura (expressões culturais e artes cênicas).

O CCL e o teatro "Pernas de Pau" também se relacionam diretamente com o contexto sociocultural da região e acabam por fortalecer sua identidade cultural e criativa. Por exemplo, o empreendimento de Júlia referente ao segmento de moda alinha-se diretamente com o fato de Caruaru e os municípios circunvizinhos, como Toritama e Santa Cruz do Capibaribe, comporem o Polo de Confecções Têxteis, um dos principais pilares econômicos da região, assim como o teatro "Pernas de Pau" relaciona-se fortemente com as expressóes culturais caruaruense e festejos típicos na época do São João.

Quadro 4 - Segmentos da Indústria Criativa

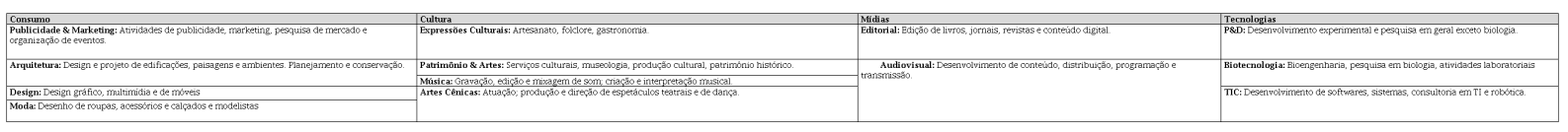

Fonte: Elaborado pelos autores baseados em dados do Firjan (2019, p. 6).

\subsubsection{Organizing e gestão ordinária}

A noção principal de organização e gestão que se pretende trabalhar neste caso para ensino aponta para o aprimoramento das Teorias da Organizações como possibilidade de caracterizar os modos de fazer administração em seu contexto social, econômico, cultural e político. Dois constructos são importantes para a discussão do caso em sala de aula: organizing e gestão ordinária. Ambos estão atrelados ao movimento da "virada prática", que, a partir dos Estudos Baseados em Práticas, tem possibilitado entender as organizações por outra óptica de conceitos quanto ao funcionamento (Schatzki, 2001, 2006, 2016; Nicolini, 2013).

Para Nicolini (2013), as abordagens das práticas são processos fundamentais e tendem a ver as organizações como uma realização rotineira e recorrente em curso. Neste mesmo sentido, Schatzki (2001) afirma que a abordagem das práticas percebe a atividade humana como meio os quais estruturas sociais seguem, e compreender as práticas específicas sempre envolve a apreensão de configurações materiais. Com esse entendimento, pretende-se chamar a atenção do estudante ao analisar os casos das organizaçóes propostas, para compreender a gestão a partir das pessoas que a realiza no seu contexto de trabalho e com suas limitações materiais e de recursos que lhe são inerentes.

Assim, Duarte e Alcadipani (2016) afirmam que o conceito de organizing se volta

Mais para os processos do que para as estruturas e no organizar mais que nas organizações, defendendo, dessa forma, um retorno ao organizar como o estudo do que as pessoas fazem quando agem coletivamente a fim de se atingir algo (p. 61).

Essa noção permite caracterizar os modelos de gestão inerentes ao Centro Criativo Local e ao Teatro de Mamulengos, evidenciando pontos de similaridade, mas, sobretudo, de divergências. Ambas as organizações apresentam processos e práticas administrativas rotineiras que são executadas aos seus modos, a sua lógica de funcionamento interna. O que se pretende ressaltar é que, embora as organizações analisadas no caso de 
ensino estejam no contexto mais amplo da economia criativa local, elas podem e devem ser compreendidas através das explanações dos processos narrados ao longo do caso.

Em concordância com Santos e Helal (2018), entende-se que a noção de organizing compreende que organização é o ponto de chegada das práticas desenvolvidas e não deve ser entendida como a análise central, como a teoria organizacional recorrente no campo tende a considerar. Os autores frisam que o que deve ser analisado são as práticas e os processos que constituem certa ordem organizativa, e não a organização como entidade. Essa análise permite evidenciar os problemas mais corriqueiros existentes nas organizações e entender os atores centrais que lidam com esses problemas e os resolvem. Esse entendimento é ressaltado por Duarte e Alcadipani (2016), no qual as diferentes realidades organizacionais devem ser compreendidas como resultados do organizar e não como conceitos tidos como certos, naturalizados ou acabados.

Nesse ponto, Santos e Silveira (2015) orientam que a preocupação ao analisar as organizações por meio de seus processos e práticas habituais deve ser com aquilo que as pessoas cotidianamente "realmente fazem" nas organizações. Por cotidiano entende-se o que é realizado no dia a dia, individualmente e em coletividade, e a partir do cotidiano e do que nele é feito. Em vista disso, o conceito de gestão ordinária permite aprofundar a análise das organizações apresentadas no caso. A gestão ordinária tem outro entendimento sobre a gestão de resolução de dilemas, por exemplo, que tem como protagonista a experiência e o saber do homem ordinário (Gouvêa, Cabana, \& Ichikawa, 2018; Carrieri, Perdigão, Martins, \& Aguiar, 2018).

Para Carrieri, Perdigão e Aguiar (2014, p. 700), a gestão ordinária acontece "no cotidiano dos negócios ordinários, dos pequenos negócios, e é uma prática social e cultural formada por uma pluralidade de códigos, referências, interesses pessoais e relacionais”. Esta definição reflete a gestão realizada em ambas organizações do caso. $\mathrm{O}$ Teatro de Mamulengos atua sobre a lógica na qual a arte não se vende, mas se repassa, que se relaciona com os interesses pessoais e relacionais de Pedro e Ana. Muitas vezes, a gestão ordinária realizada no teatro pode ser vista pela visão comum da teoria das organizações como uma gestão não profissional ou até mesmo amadora, mas a partir da ideia da gestão ordinária entende-se que esta gestão se dá pelo conhecimento adquirido no saber e fazer do e no cotidiano (Carrieri et al., 2018), o que também é passível de ver no Centro Criativo Local. No caso de Júlia, é possível perceber uma empreendedora que está iniciando no ramo e que desenvolve um projeto de negócio ainda incipiente, e está tentando lidar constantemente com problemas organizacionais que caracterizam e limitam o modo de gestão adotado.

Dessa maneira, como resolução da segunda questão e que permeia a compreensão para a resolução das questões seguintes, propõe-se o entendimento de que gestão ordinária é captar e compreender a gestão feita por pessoas comuns em seu cotidiano, como os personagens principais do caso, Pedro, Ana e Júlia, assim como as "estratégias e práticas de sobrevivência utilizadas no dia a dia" por seus praticantes (Barros \& Carrieri, 2015, p. 159). As formas de organizar, que diferem em ambas as organizações, podem ser explicadas mediante a forma processual da gestão, sem perder contato com a natureza mundana da vida cotidiana e a natureza concreta e material das atividades com as quais os personagens estão envolvidos (Nicolini, 2013).

A segunda questão tem como intuito a reflexão acerca da gestão ordinária, das dificuldades do cotidiano, da economia criativa e do contexto. Outras questões podem ser apontadas, como a CCL ter processos e etapas a serem cumpridas, tais como o lançamento do edital de seleção para incubação, o apoio e organização das quatro etapas da incubação, o agendamento de consultorias, entre outras, e o teatro "Pernas de Pau" ter os ensaios, o espetáculo semanal, a venda dos lanches, as oficinas, a confecção dos bonecos e animações de festas.

Indica-se como resolução para terceira questão que, no CCL, apesar da estrutura bem organizada e dos maquinários serem considerados de excelente qualidade, existem algumas dificuldades, como a falta materiais e insumos para impressora em 3D, a falta de treinamento para lidar com os maquinários, dificuldade em contactar os consultores nos momentos de dúvidas, como no caso de Júlia com o plano financeiro, e os adiamentos das reunióes com os consultores. Sugere-se que os estudantes façam o exercício de reflexão de se imaginar na situação dos personagens: precisa-se concluir o projeto no prazo que está apertado e faltam ferramentas e materiais. Que solução e decisão criativa podem ser tomadas? Uma possível saída criativa para 
este dilema pode ser a rede de relacionamentos (networking) proporcionados pelo espaço do CLL, buscando por intermédio dessa rede quem saiba utilizar os maquinários e possa ensinar, assim como na elaboração do planejamento financeiro.

Por fim, estas questões foram pensadas para que os estudantes observem os diferentes tipos de organizações, gestões ordinárias e o contexto das organizações. Entende-se como resolução possível para a quarta questão as organizações pertencerem à economia criativa e sua lógica de atuação, dificuldades e gestão variadas (Duarte \& Alcadipani, 2016). O grupo de teatro "Pernas de Pau" não trabalha pela racionalidade instrumental predominante na administração (Barros \& Carrieri, 2015), ou seja, o lucro como fim, mas como meio para perpetuar a cultura popular, e esse entendimento é o desafio para os estudantes na resolução da quarta questão.

Esse aspecto ganha destaque quando Pedro afirma que não cobra pela entrada, pelas oficinas e não pensa em vender os bonecos de mamulengos. A principal dificuldade no cotidiano da organização está relacionada ao pouco recurso para manutenção do teatro como um todo, visto que dependem do público que comparece aos domingos e aos shows particulares. Uma solução pensada a partir da gestão do teatro por Pedro e Ana, considerando a filosofia de gestão adotada de que "cultura popular não se vende, se repassa", seria solicitar aos participantes da oficina que levem os materiais necessários, divulgar mais intensamente as apresentações, utilizar materiais recicláveis, buscar apoio com setor público, aumentar o comércio de lanches etc. Outras soluções criativas podem ser visualizadas além destas pelos estudantes.

Assim, o conceito de gestão ordinária aqui trabalhado possibilita visualizar e compreender como acontece a organização da gestão aos moldes que as organizações apresentadas neste caso para ensino, o Teatro de Mamulengo "Pernas de Pau" e do CCL, fazem sua gestão no (e a partir do) cotidiano. Entender os problemas e demandas diários através na ideia de organizing, atrelada ao conceito de gestão ordinária, feita por pessoas comuns, foge dos modelos hegemônicos tradicionalmente presentes na teoria organizacional e administração. Foi esta inquietação teórica que se buscou desenvolver ao longo desta proposta de ensino. Tão importante quanto trazer exemplos da realidade de práticas de gestão ordinária é entender como o Teatro de Cultura Popular e o CCL, mesmo sendo ambos pertencentes à EC local, possuem especificidades distintas, tais como, investimentos, reconhecimento e estimas socioculturais diferentes. Espera-se que este caso para ensino fomente a discussão sobre a gestão ordinária com o olhar atento ao contexto econômico local e aos processos corriqueiro presentes nas organizações ordinárias.

\subsection{Indicações bibliográficas}

Carrieri, Alexandre de Pádua, Perdigão, Denis Alves, \& Aguiar, Ana Rosa Camillo. (2014). A gestão ordinária dos pequenos negócios: outro olhar sobre a gestão em estudos organizacionais. Revista de Administração (São Paulo), 49(4), 698-713.

\section{REFERÊNCIAS}

Alberton, A., \& Silva, A. (2018). Como Escrever um Bom Caso para Ensino? Reflexões sobre o Método. Revista de Administração Contemporânea, 22(5), 745-761.

Barros, Amon, \& Carrieri, Alexandre De Pádua. (2015). O Cotidiano E A História: Construindo Novos Olhares Na Administração. Revista De Administração De Empresas, 55(2), 151-161.

Britto, Jorge Nogueira de Paiva. (2016). A regional perspective of the creative economy in brazil. Revista de Economia Contemporânea, 3(20), 458-491.

Carrieri, A. P., Perdigão, D. A., \& Aguiar, A. R. C. (2014). A gestão ordinária dos pequenos negócios: outro olhar sobre a gestão em estudos organizacionais. Revista de Administração, 49(4), 698-713. DOI: https://dx.doi.org $/ 10.5700 /$ rausp 1178 
Ítalo da Silva, et al. Organizing e Gestão Ordinária na Economia Criativa local

Carrieri, A., Perdigão, D., Martins, P., \& Aguiar, A. R. C. (2018). A Gestão Ordinária e suas práticas: o caso da Cafeteria Will Coffee. Revista De Contabilidade E Organizaçôes, 12, e141359.

Duarte, Márcia Freitas, \& Alcadipani, Rafael. (2016). Contribuições do organizar para os estudos organizacionais. Revista Organizações \& Sociedade, 76(23), 57-72.

Firjan. (2019). Mapeamento da Indístria Criativa no Brasil. Sistema FIRJAM SENAI. Rio de Janeiro, RJ: fev.

Gouvêa, J. B., Cabana, R. P. L., \& Ishikawa, E. Y. (2018). As histórias e o cotidiano nas organizações: uma possibilidade de dar ouvidos àqueles que o discurso hegemônico cala. Farol - Revista Brasileira de Estudos Organizacionais, 5(12), 297-347.

Kon, Anita. (2016). On the creative economy chain in Brazil: potential and challenges. Brazilian Journal of Political Economy, 1(36), 168-189.

Martins, G. A. \& Theóphilo, C. R. (2009). Metodologia da investigação cientifica para ciências sociais aplicadas. 2 ed. São Paulo: Atlas.

Machado, R. M. (2009). Da indústria cultural à economia criativa. ALCEU, 9(18), 83-95, jan/jun.

Nicolini, Davide. (2013). Practice Theory, Work, \& Organization: an introduction. Oxford: Oxford University Press.

Oliveira, J. M. de., Araujo, B. C. de \& Silva, L. V. (2013). Panorama da Economia Criativa no Brasil. Texto Para Discussão 1880, Instituto de Pesquisa Econômica Aplicada (IPEA). Acesso em: 22/04/19.

Roesch, S. M. A. (2007). Notas sobre a construção de casos para ensino. Rev. adm. contemp., Curitiba, 11(2), p. 213-234.

Schatzki, T. R. (2001). Introduction: practice theory. In: Schatzki, T. R.; Knorr Cetina, K.; Von Savigny, E. (eds). The practice turn in contemporary theory. New York: Routledge.

Schatzki, T. R. (2006). On Organizations as they happen. Organizations Studies, 27(12), 1863-1873.

Schatzki, T. R. (2016). Practice theory as flat ontology. In: Spaargaren G., Weenink D., \& Lamers, M. (eds). Practice Theory and Research. New York, NY: Routledge.

Serra, N. \& Fernandez, R S. (2014). Economia Criativa: da discussão do conceito à formulação de políticas públicas. Revista de Administração e Inovação (RAI), (11) 4, São Paulo - SP, out./dez, p. 355-372.

Santos, L. L S., Silveira, R. A. (2015). Por uma epistemologia das práticas organizacionais: a contribuição de Theodore Schatzki. Revista Organizaçôes \& Sociedade, 22(72), 79-98, jan./mar

Santos, E. C., \& Helal, D. H. (2018). Maracatu, trabalho e organizing. Revista de Administração Contemporânea, 22(4), 620-638, julho/agosto.

SEDEEC. (2019). Secretaria de Desenvolvimento Econômico e Economia Criativa de Caruaru.

UNCTAD. (2008). Creative Economy Report. The challenge of Assessing the creative Economy towards Informed Policymaking. United Nations/UNDP/UNESCO.

UNCTAD. (2010). Creative Economy Report 2010. Creative Economy: A feasible development option. United Nations/UNDP/UNESCO.

UNCTAD. (2013). Creative Economy Report 2013 Especial Edition. Widennning local development pathways. United Nations/UNDP/UNESCO.

Zappellini, M., \& Feuerschütte, S. (2015). O Uso Da Triangulação Na Pesquisa Científica Brasileira Em Administração. Administração: Ensino e Pesquisa, 16(2), 241-273. 